\title{
The Study on Factors Influencing Translation Variation
}

\author{
Wanfang Zhang ${ }^{1,}$, , Xiangxin Liu ${ }^{2, \text { b }}$ \\ ${ }^{1}$ School of Foreign Languages, Wuhan Polytechnic University, Wuhan, 430028, China \\ ${ }^{2}$ Department of Public Relations, Wuhan Railway Vocational Technological University, Wuhan, \\ 430028, China
}

aemail: 594561792@qq.com, bemail: 420300466@qq.com

\begin{abstract}
Keywords: Chinese translation theory; translation variation; translation variation factors
\end{abstract}
\begin{abstract}
Stepping into the late 1990s, translators started to focus on theoretic items of "the theory of poly-system", "deconstructivism", "feminism" and etc. In traditional translation views, translation is equal to full translation, while amplification, deletion, edition, narration, contraction and adaptation cannot be called faithful translation. Only today when translation develops rapidly and the exchange of information goes on continuously will translation variation come into light and go hand in hand with complete translation in the arena of translation. This paper gives a full play to the factors influencing translation variation and lays more emphasis on the reflection on the current situation of translation variation.
\end{abstract}

\section{Introduction}

On the stage of Chinese translation, there have been frequent views on reflections of the relationships between Chinese translation theory and foreign translation theory. Actually from the domestic situation of translation theories we can see that foreign translation theories fill almost every field. Traditionally, a theory is borrowed from abroad without considering whether it is reasonable or significant or whether it accords with the actual situation of domestic translation. In view of this reality, there has been continuous claim of many scholars to establish translation theories with Chinese characteristics. The translation variation theory brought up by Prof. Huang Zhonglian is an original research which is deeply rooted in the practice of Chinese translation. As a matter of fact, focusing on scientific translations, the translation variation theory fills in the blank, because other genres of translations except for literary and academic translations have never been attached importance. Even there are some innovative theories, most of them deal with the summaries of techniques and words, lacking of theoretical and systemic matters. However, the translation variation theory represents a great progress in the development of Chinese translation theories.

\section{Factors Influencing Translation Variation}

In the process of translation variation, there are many factors influencing the translation activities, which can be called the manipulation phenomenon. This paper will take the macro perspective of the manipulation school as reference to make a research on the factors influencing translation variation and lay emphasis on the influence of cultural difference, ideology, translators and the power of patronage.

The influence of cultural difference on translation variation. Language is the carrier of culture as well as an important fragment of it. In American linguist E. Spair famous work language, he mentions that language cannot exist without culture and all kinds of practices and beliefs passed down by society, which plays a decisive role in our life. Culture includes everything in human society; therefore language belongs to the category of culture. With the development of human society, language makes some progresses too. Language is closely connected with practical activities in society. However, words are the most active element in language, which can reflect the features of culture mostly and the changing part of social life and thinking. For successful 
translations, being familiar with two cultures is more important than having a good knowledge of two languages. That is because words are only meaningful in corresponding cultural backgrounds." Translation require that translators convey domestic cultural values and souls while having a good knowledge of foreign cultural views, beliefs, custom, standards of values and so on. Therefore, translators need to possess bilingual abilities as well as bi-cultural or even multicultural knowledge, especially having some knowledge of the national psychological consciousness, cultural formation process, historical custom and traditions and geographical features of the two languages. The famous linguist Edward said in The Theory of Language that "language is a kind of environment, people speaking the same language belong to the same ethnic, that is to say they belong to conglomerates which carry different features. Besides, language cannot exist without culture, which means that language cannot be passed down separated from society." (Edward Spair, 1985)

The influence of ideology on translation variation. Ideology acts as a constraint on the select of source text. The selection of the material to be translated will be the very beginning of the translation activity. This choice may be influenced by many factors, but the patronage's or the translator's ideology together with the collective ideology of that time must be the most important. More often than not, what determines whether or not a foreign text will be translated is not the "intrinsic value" of the text, but the actual need in the target culture considered by the initiator or the translator. Although the ideological factor is not the factor which constrains the translator's selection of works for translation, the political factor, which is the most important facet of ideology, plays an important role in the process. Apart from political factor, other aspects of ideology like cultural conventions and aesthetic tradition also manipulate the translator's choice of works and materials for translation. Those factors govern the choice of text types or even individual texts to be imported through translation into a particular culture at a particular point of time. In a word, the choice of a source text is determined by the interests, aims and objectives of the target culture.

Firstly, ideology has an impact on the selection of text in the process of translation variation. Generally speaking, which kind of text of translation translators choose depends on the ideology of the target language. The information conveyed by the original text should accords with or basically accords with the requirements of the ideology of the target language. The famous translator Tu An said when talking about the factors influencing translation, "the influence of ideology on the selection of translation works is of great significance, which is a fact." Let us analyze the translations of China in the 1950s firstly. At that time, China was a new-born socialist country, where the policy carried out is to imitate that of the Soviet Union. This policy's influence on translation was that a large number of Russian works were translated into Chinese. In the year of 1950, translation of Russian works surmounted 1662 kinds, making up $77.5 \%$ of the total number. On the contrary, English translation was only 382 kinds, making up 18\%. From 1949 to 1958, foreign literary books published in China reached more than 110 million periods, 5300 kinds, of which Russian and Soviet literature were 3500 kinds, making up 65.8\%. Nevertheless, translations of Russian and Soviet works were only regarded as books for the revolution and progress, while other literary schools were excluded. Especially in the Cultural Revolution, a number of critical works of translation came into being, including memoirs of European and American political outlines, works of Japanese militarism writers, modern Latin American novels and so on.

Secondly, ideology has an impact on the understanding of the original text in the process of translation variation. After selecting materials of translations, readers as translators should have interpretations of the original language at the beginning. And the process of interpretation is destined to be influenced by translators' stance of ideology and cultural identities. In other words, after interpreted by readers coming from different ideology, translations of the same text would be quite different; that is to say, there are one thousand Hamlets in the eyes of one thousand readers. Language is not only the carrier of information but also the carrier of culture, as a result, the living environments, views of points towards the world of different nations are various, which leads to the formations of different cultural models. Translators often interpret the unknown by means of the well-known ones. Therefore, in the process of cross-cultural communication of translations, translators would integrate their personal experience of life, models of thinking, ways to 
acknowledge, aesthetic temperament and interest, and cultural and historical backgrounds into the process of translations. For instance, when the Buddhism was introduced into China and integrated with the Taoism, many concepts of the Taoism were borrowed.

Thirdly, ideology has an impact on the strategies of translations in the process of translation variation. Translations are not going on in a vacuum, and they are always printed with the marks of translators' time of living and the culture of the target language. The French writer Hugo said vividly: translation is a kind of infringement to the target country. When introducing foreign cultures, the translators are not able to stay away from the impacts of ideology and need to take the requirements of the patronage, interest of readers and ability of accepting into consideration, then make adjustments of the strategies of the original text.

From the analysis above, we can see that ideology has been exerting significant impacts on all respects of translation variation, firstly on translators' selection of materials, secondly on the understanding of the original text, thirdly on the strategies of translations in the process of translation variation.

The influence of translators on translation variation. As the scholar of the manipulation school Lefevere pointed out, literary translation in fact is not the process of how to conform to or make use of rules, but the process for translators to make choices. The reason why translators make their own choices in the process of translation is dependent on their pre-understandings. Generally speaking, the pre-understandings of translators include congenital factors and nurtured factors. Here, I will discuss three aspects of translators' influence on translation variation: the literacy, interest and mindsets of translators.

Firstly, the literacy of translators has an impact on translation variation. Mr.Yu Guangzhong once wrote the article The Writer, Scholar and Translator to discuss specifically that translators should be armed with profound literacy. He said: "if a country wants to make progress in culture, it should dependent on a large group of professional readers to lead common readers. Among all varieties of professional readers, translators play important roles as professional readers. In principle, translators must be scholars firstly because they cannot be innocent. Their knowledge melts in translation works. Besides, translators should reach the level of writers, theoretically, why do they have to own the literacy of scholars? The psychologist Hull Baht told us through his own theories: the bigger limitation level is, the more difficult it is for attention and acknowledge id to occur. However, the limitation does not come out of nowhere, while it is produced on the basis of nurtured accumulation, that is to say, it dependents on people's literacy. Therefore, the literacy level of translators decides that of their cognitive limitation and what kind of original works is able to enter their horizons. It also plays a decisive role in the translators' understanding degree of the works and the expressions of the translations. There are two components of the literacy of translators: accumulation of knowledge and experience of lives and works.

Secondly, the interest of translators has an impact on translation variation. The interest of translators can be divided into two categories: the social utilitarian type and the academy-oriented type. Translators of the former would attach importance to the fact whether requirements of the original work can match with those of the translations when selecting materials consciously; translators of the latter are sensitive to the fact whether the academic value of the original work could match with their academic interest. Translators of different types would have various points of view and judgments towards the same original work. For the same work of Nietzsche, Lu Xun found out that Nietzsche is passionate and his works are beneficial to the needs of the old China; while Wang Guowei saw the aesthetic views of Nietzsche and applied them to the research of A Dream of the Red Mansions.

Thirdly, the mindsets of translators have an impact on translation variation. As Lefevere pointed out: "mindsets influence translators' selections of texts and also decide the ways to translate these texts." The common mindsets of translators are: to maintain the purity of the translations, to understand the translations, to prefer free translation of literal translation, to pursue what views of the translations and so on. Lefevere's research showed that the majority of translators in Victoria Age have a lot in common: they attached great importance to maintaining the purity of contents and 
thoughts of translations; therefore, many translators deleted the so-called lewd contents in the texts.

The influence of the power of patronage on translation variation. Since in Andre Lefevere's Three Principles Theory the patronage is regarded as the most important factor, there is no doubt that the patronage exerts significant impacts on translation activities and he or she keeps influencing the process of translation activities. Some powerful individuals can manipulate translation activities by their outstanding achievements, capital advantages or other influential powers, which are reflected in the establishment of translation criteria, the selective direction of translations and the usage of different translation strategies. Patronages such as classes, government departments and religious groups could directly determine the rise and fall of translation activities. Patronages of this type tend to be relatively powerful and they could add pressure to the translator in the selection of texts and the process of translation by applying their power and taking advantage of the ideology, then have some influences on the circulation and development of the thoughts of translations. Patronages exert impacts on the translator's selection of materials. The translator tends to cooperate because of privileges and pressures from all aspects. As a translator and a thinker, though Yan $\mathrm{Fu}$ has his own clear goals and ideas, his translations also are controlled by the ideology of the patronage because he is an official of the Qing Dynasty.

\section{Conclusion}

Factors influencing translation variation includes cultural difference, ideology, translators and the power of patronage. In a more detailed way, firstly, the influence of cultural difference on translation variation includes the difference of thinking models, the difference of religions and beliefs, the difference of customs and the difference of myths and legends and classic works; secondly, ideology influences the selection of text, the understanding of the original text and the strategies of translations respectively; thirdly, the literacy, interest and mindsets of translators exert impacts on translation variation; last but not the least, patronage plays an important role in translation variation. This paper strives to make an elaboration on the features of the translation variation theory, in order to give a profound reflection on them and then to realize the factors influencing translation variation theory.

\section{Acknowledgement}

This research was supported by English and Chinese Translation of 2015 Exquisite Courses Resource of Wuhan Polytechnic University.

\section{References}

[1] Fawcett, P. Translation and Language: Linguistic Theories Explained [M]. Manchester: St Jerome Publishing, 1997.

[2] Gentzler, Edwin.. Contemporary Translation Theories [M]. London \& New York: Routledge, 1993.

[3] Newmark, Peter. Approaches to Translation [M]. Shanghai Foreign Language Education Press, 2002.

[4] Nida, Eugene A. \& Charles R. Jaber. The Theory and Practice of Translation [M]. Netherlands: E. J. Brill, Leiden, 1969.

[5] Edward Spair. A Theory of Language [M]. Beijing: Beijing Business Press, 1985.

[6] Huang Zhonglian. The study of Translation Variation [M]. Beijing: China Translation \& Publishing Corporation, 2015. 